\title{
¿Como son las redes de los individuos en situación de pobreza en el Brasil urbano?
}

\author{
Eduardo Marques - Universidade de São Paulo, Brasil ${ }^{1}$
}

\begin{abstract}
Resumen
Este artículo presenta los resultados de una investigación reciente sobre las redes sociales de individuos pobres que viven en Sao Paulo, Brasil. La investigación ha levantado y analizado las redes de 209 individuos pobres que habitan siete espacios de la ciudad sometidos a distintos grados de segregación residencial, así como treinta individuos de la clase media. El presente trabajo presenta las principales características de las redes, así como explora el patrón de intensa variabilidad observada en las redes, incluso entre los individuos pobres. Los resultados indican la existencia de patrones claros de variación de las redes según su tamaño, estructura e inserción urbana, además de la sociabilidad que contienen, lo que permitió la construcción de una tipología de las redes y de las sociabilidades. La asociación entre segregación social en el espacio y las redes refuta la existencia de efectos directos de la primera sobre las segundas, pero sugiere que las redes efectivamente pueden conectar una parcela de los individuos espacialmente aislados por la segregación, aunque sólo en el caso de una parte reducida de las personas en situación de pobreza.
\end{abstract}

Palabras clave: redes personales, sociabilidad, pobreza, Sao Paulo.

\begin{abstract}
This article presents the results of a recent investigation on social networks of poor individuals who live in São Paulo, Brazil. The research analyzed the networks of 209 individuals in poverty who live in seven different locations of the city and are submitted to several degrees of urban segregation, as well as 30 middle-class individuals. This article presents the main characteristics of the networks, as well as explores their intense variability according to size, structure, urban integration and the sociability in which they are embedded, leading to the construction of typologies of networks and of sociabilities. The association between social segregation in space and networks is not direct, although suggests that the networks can really connect a part of the individuals who are spatially isolated by segregation, even if this effect impacts only a part of the individuals in poverty.
\end{abstract}

Key Words: personal networks, sociability, poverty, Sao Paulo.

Las redes sociales han sido citadas intensamente en la sociología urbana y en estudios sobre pobreza como una de las dimensiones importantes para la producción de capital social y de situaciones de pobreza urbana. También han sido indicadas como uno de los principales elementos que explican las dinámicas comunitarias fundamentales para la sociabilidad local. Aunque a veces de manera implícita, se considera que la segregación influencia las redes y que los individuos más segregados espacialmente tienden al aislamiento social.

\footnotetext{
1 Profesor del Departamento de Ciencias Políticas de la USP (DCP/USP) e investigador y director del Centro de Estudos da Metrópole del Cebrap (CEM/Cebrap). ecmarq@uol.com.br
} 
A pesar de la importancia de estas dimensiones son raros los trabajos que analizan empíricamente las características de las redes, así como sus consecuencias para las situaciones de pobreza. El presente artículo expone una parte de los resultados de una investigación más amplia que explora las redes sociales de individuos en situación de pobreza urbana en Sao Paulo sometidos a distintas situaciones de segregación, especificando las características de estas redes, sus consecuencias para la pobreza, así como los mecanismos que median la producción de tales consecuencias. El presente artículo ofrece una caracterización general de estas redes, incluso de su interacción con la segregación social en el espacio, la cual se entiende como la separación de los grupos sociales en espacios relativamente homogéneos internamente ${ }^{2}$. Como veremos, el patrón encontrado es bastante heterogéneo, aunque es posible delimitar patrones claros por detrás de tal variabilidad. En lo que respecta a la segregación, el artículo refuta la existencia de una relación mecánica sobre las redes, pero indica que ciertos tipos de redes ayudan a conectar algunos individuos segregados, aunque otras personas están efectivamente sometidas a aislamientos cumulativos de naturaleza social y espacial.

El artículo se divide en tres partes, además de esta introducción y de la conclusión. En la primera sección resumo las principales contribuciones sobre el tema, no tanto con el objetivo de reseñar el debate sino para construir conceptualmente el objeto estudiado, así como describo la investigación realizada. En la sección que se sigue presento las principales características de las redes y las comparo con las de la clase media. Una vez que la heterogeneidad de las redes es uno de los principales resultados obtenidos, exploro en la tercera sección su variedad por medio de la realización de tipologías de las redes y de la sociabilidad de los individuos cruzándolas a continuación para especificar las situaciones relacionales existentes. Al final, sintetizo los principales resultados encontrados.

\section{Conceptuación de las redes y presentación del diseño de la investigación}

El análisis de redes sociales es un campo de estudio relativamente reciente que parte del la premisa de que el centro de las atenciones del análisis social debe ser las relaciones y no los atributos de las entidades sociales (Emirbayer, 1997). Aunque la idea se remonta a la misma ontología social considerada por clásicos como Simmel (1973 [1902]) y Weber (1999 [1922]), el desarrollo de un instrumento de análisis y de un método a partir de los años 1930, pero en especial desde los años 1970 (Freeman, 2004) ha permitido que se avanzase analíticamente más allá de las metáforas y se investigase sistemáticamente los efectos de los patrones de relaciones entre entidades sociales

\footnotetext{
2 Para los demás resultados remito el lector a Marques (2009).
} 
sobre innumerables fenómenos sociales. Estas entidades pueden incluir cualquier agente social potencial, tales como individuos, grupos, movimientos y organizaciones, por ejemplo, y considerar como relaciones la circulación de bienes materiales como dinero, personas y recursos, y aun elementos inmateriales como ideas, afecto, etc.

En términos de métodos, esta literatura utiliza dos formas para investigar los patrones de vínculos: a través de las llamadas redes totales, al estudiar parcelas o redes enteras de contextos sociales específicos, o a través de redes personales que incluyen los contactos de la sociabilidad de cada entidad social.

En la primera línea de análisis, el diseño de investigación intenta abarcar las relaciones consideradas como importantes en un contexto social dado, siendo que los límites construidos analíticamente consideran una cierta circunscripción sectorial específica de la realidad social. Esto abarca una vasta gama de estudios que incluyen estudios de organizaciones, así como las dinámicas internas de agencias estatales y sus políticas (Laumann y Knoke, 1987; Marques, 2000 y 2003), las interacciones de organizaciones en estructuras de lobby (Heinz et. Al., 1997) o los comités gestores de cuencas hidrográficas (Schneider et. Al., 2003). Además de ello, se pueden estudiar comunidades específicas delimitadas temática o físicamente como las relaciones de amistad en el interior de la elite financiera (Kadushin, 1995), las redes empresariales en Sao Paulo (Toledo, 2005), la red de la elite política paranaense (Nazareno, 2004), las redes de músicos y las transformaciones de los estilos musicales (Kirschbaum, 2006), las redes entre asociaciones civiles (Gurza Lavalle et al., 2007), las redes personales en el interior de una unidad productiva (Silva, 2003) o las redes en un asentamiento informal bajo la intervención del poder público (Pavez, 2006). Por fin, y analizando las dinámicas políticas y sociales en un sentido más amplio, los estudios pueden enfocar campos de acción política y social tan distintos como la consolidación de un partido político en nivel nacional (Hedstrom et al., 2000), las relaciones sexuales entre adolescentes (Bearman et. Al., 2004) y las movilizaciones estudiantiles (Mische, 2008).

Otra forma de abordar la cuestión, sin embargo, es investigar las redes individuales, centradas conceptual y empíricamente en torno a individuos específicos denominados egos. En esta línea de análisis se inscriben estudios tan distintos como los de Beggs (1986) que comparó las redes de contextos urbanos y rurales, de Moore (1990) que realizó la misma tarea pero con redes de hombres y mujeres, de Grossetti (2005) que investigó los orígenes sociales de los vínculos, de Bidart y Lavenu (2005) sobre los efectos del ciclo de vida y de los eventos sobre las redes, de Campbell y Lee (1992) sobre la integración social y las redes, y los estudios de Maya-Jariego (2003) sobre la integración de inmigrantes internacionales. En el caso de Brasil, los estudios sobre redes 
personales son aún más escasos que aquellos acerca de las redes totales, con las excepciones de Soares (2009) que estudió los efectos de las políticas de remoción habitacional sobre las redes de vecinos, y de Fontes y Eichner (2004) sobre las redes personales en un asentamiento informal en Recife.

En un sentido estricto, las redes individuales son un caso particular de red en contextos sociales específicos, al considerarse como contexto la sociabilidad de un individuo dado. Sin embargo, estas redes presentan particularidades conceptuales y metodológicas. Aunque las redes sociales que estudiamos siempre representen recortes analíticos de contextos relacionales más amplios, en el caso de las redes individuales es mayor el grado de artificialidad del ejercicio analítico (necesario) de "recortarlas" de los contextos en que se insertan. Sin embargo, también en este caso la ontología considerada es enteramente relacional y los recortes son apenas artificios metodológicos para viabilizar la investigación.

Cuando se consideran sólo las relaciones directas del individuo y las eventuales relaciones entre sus contactos primarios, o sea, sólo las relaciones directas que se encuentran a un paso de distancia del ego como máximo, trabajamos con las llamadas redes egocentradas. La mayor parte de los estudios de redes individuales existentes trabaja con este tipo de red, en especial por el hecho de que estas redes pueden ser reproducidas a partir de datos obtenidos a través de encuestas por muestreo.

Otra estrategia de análisis de redes individuales es considerarlas como redes personales, construidas sin que se limite previamente la extensión de la red, en que también se levantan los vínculos indirectamente conectados al ego sin limitar previamente la distancia, teniendo siempre en cuenta su sociabilidad. La consideración de las redes personales evita los problemas causados por la limitación apriorística de los vínculos inherente a la estrategia de las redes egocentradas, aunque presenta dificultades para la producción de investigaciones representativas de las poblaciones.

En esta investigación opté por analizar las redes personales y no las redes totales o las redes egocentradas en individuos, ya que considero que una parcela importante de la sociabilidad que influencia la pobreza y las condiciones de vida está centrada en los individuos (diferentemente de las primeras), pero ocurre a distancias mayores que su entorno inmediato (diferentemente de las segundas). Esta decisión se mostró acertada, pues las redes encontradas variaron entre cinco y 148 nodos, variabilidad que no podía ser captada por las redes egocentradas. 
La investigación involucró el levantamiento de las redes personales de 209 individuos que habitan siete distintas localidades que concentran pobreza en Sao Paulo conventillos en el área central, un asentamiento informal en un área de clase media (Jaguare), un asentamiento informal en un área de clase alta (Paraisópolis), un asentamiento informal en la periferia (Vila Nova Esperança, en Taboao da Serra), un conjunto habitacional en la periferia (Cidade Tiradentes), un mixto de lotes irregulares y asentamiento informal en la periferia (Jardim Angela) y un asentamiento informal en un distrito industrial (Guinle, en Guarulhos). La elección de las localidades tuvo como objetivo la construcción de una muestra intencional de las situaciones habitacionales y de pobreza presentes en la metrópolis, y fueron realizadas 30 entrevistas en cada localidad entre septiembre de 2006 y agosto de 2007. Para construir un patrón de comparación levanté 30 redes de individuos de la clase media utilizadas como referencia para el estudio de las demás redes.

En cada una de estas localidades fueron realizadas entrevistas egocentradas ${ }^{3}$ con un cuestionario semiabierto y un generador de nombres. La elección de los entrevistados en cada campo ocurrió de forma aleatoria a lo largo de los recorridos por las localidades estudiadas, y los individuos fueron abordados ya sea en los espacios públicos o en la entrada de sus casas, tanto en días de semana como durante los fines de semana. En algunos casos, el ingreso en las localidades de estudio fue mediado por informantes que habían participado de investigaciones anteriores o miembros de movimientos asociativos locales. A lo largo del trabajo en cada campo la muestra de entrevistados fue controlada por algunos atributos sociales básicos como sexo, edad, status migratorio y ocupacional, y área de domicilio en la localidad estudiada. Este control tuvo como objetivo garantizar una proporcionalidad razonable de las características medias de la población local y evitar la constitución de sesgos. La comparación entre las características de los entrevistados y de la población estudiada sugiere que este objetivo fue alcanzado con bastante éxito.

La clase media fue definida de manera amplia, mezclando criterios de ingreso con ocupación, e incluyó profesionales liberales, funcionarios públicos, personas involucradas con actividades intelectuales y dueños de establecimientos comerciales de cierto porte. La delimitación del grupo no siguió mayores preocupaciones conceptuales o metodológicas una vez que el objetivo de estas entrevistas era sólo constituir un patrón de comparación para el análisis de las redes de los individuos en situación de pobreza.

\footnotetext{
${ }^{3}$ Entrevistas en que se pregunta al individuo acerca de su propia red y sociabilidad.
} 
Estas informaciones fueron posteriormente tratadas con herramientas de análisis de redes sociales, resultando en 239 redes personales. A continuación exploré las diversas características de las redes de los individuos en situación de pobreza accediendo a sus principales condicionantes y a los procesos que influyen en su formación y su dinámica, comparándolas a las redes de clase media. Fueron estudiados los procesos de creación y ruptura de vínculos, las dinámicas de homofilia ${ }^{4}$ y los condicionantes sociales de la construcción y mantenimiento de las redes. La homofilia se refiere al hecho de que los involucrados en una díada tienen una misma característica, cualquiera que sea, como sexo, color de piel, clase social, localidad de domicilio, etcétera (McPherson et al., 2001). Las redes varían según diversos atributos y variables específicos, incluyendo sexo, ciclo de vida, estatus migratorio y ocupacional, entre otros. De forma general, prácticamente no existen relaciones entre los individuos en situación de pobreza y personas de grupos sociales y de ingreso distintos a los suyos. Esta es tal vez una de las más importantes características de estas redes relacionadas a la reproducción de la pobreza y la desigualdad social. Naturalmente, la cuestión no se origina en las redes, sino que representa sólo una faceta relacional de la estructura social.

Posteriormente elegí un conjunto de redes para emprender la parte cualitativa de la investigación, a partir de la combinación de los tipos de redes, los campos estudiados y las características personales de los entrevistados. Se realizaron entrevistas cualitativas con veinte individuos en las que se exploraron las transformaciones de las redes desde las primeras entrevistas, así como su utilización por las personas en el cotidiano para la solución de problemas. Estos datos me permitieron comprender la dinámica de los patrones relacionales y su movilización por los individuos, así como delimitar los mecanismos sociales responsables tanto por la constitución y transformación de las redes como por su movilización por los individuos en sus prácticas.

En este artículo se presentan las características y la variabilidad de las redes.

\section{Las redes y la sociabilidad de los individuos en situación de pobreza}

Para cada red fue generado un conjunto de medidas. Las medidas de red señalan las características de los patrones relacionales de tal modo que es posible analizar las posiciones y su estructura, así como compararlas entre si. Debido al sentido de este trabajo, los detalles técnicos y operacionales para la producción de las medidas importan poco, siendo mucho más importante tener en cuenta su significado respecto a los

\footnotetext{
${ }^{4}$ La homofilia describe la propensión de los individuos a relacionarse con personas que tienen atributos similares a los suyos. Cada atributo, por lo tanto, define un tipo de homofilia como la de sexo, de edad, de color, de piel, etc.
} 
procesos sociales involucrados 5 . Se generaron dieciocho medidas consideradas como indicadores de tamaño, cohesión, conectividad, formación de grupos, actividad relacional, estructura de la red egocentrada, variabilidad de la sociabilidad y localismo ${ }^{6}$. Varias de ellas se encontraban altamente correlacionadas entre si, siendo fundamental determinar las dimensiones sociales singulares subyacentes a los datos. El análisis de los patrones de asociación entre las medidas indicó como dimensiones más importantes de las redes su tamaño (medido por el número de nodos), la variabilidad de la sociabilidad (medido por el número de esferas de sociabilidad) y su localismo (medido por la proporción de individuos fuera de la localidad de domicilio ${ }^{7}$. Las esferas de sociabilidad son "espacios" de sociabilidad cognitivamente definidos. No se trata de la delimitación de tipos de vínculo, ni tampoco de espacios físicos, sino que son partes de la sociabilidad de los individuos tal como ellos la comprenden (Marques, 2009).

Vale notar las diferencias consideradas aquí entre localismo y segregación, pues ambas dimensiones espaciales de las redes. El localismo es una característica de cada red asociada a la proporción de los vínculos existentes dentro o fuera de la localidad donde vive el ego. Técnicamente se trata de un tipo de homofilia - de localidad de domicilio. La segregación, por el contrario, es una característica de la distribución de los grupos sociales en el espacio relativa a la existencia de homogeneidad y separación entre grupos en el territorio de la ciudad (Marques, 2005). Las redes pueden variar según diversas divisiones (como género y edad), incluso según el grado de segregación de la localidad del domicilio. Para que se comprenda el fenómeno, traté el localismo de las redes de forma similar a las demás características de las redes, observando su variación según la segregación de la localidad de domicilio.

Observemos entonces las características generales de las redes. Las redes de los individuos en situación de pobreza tienen en promedio 53 nodos. En el conjunto de la muestra, sin embargo, las redes varían entre cuatro y 179 nodos. El número de vínculos sigue el mismo camino, con un promedio de 107 nodos y una amplitud total entre siete

\footnotetext{
5 Para medidas y procedimientos, v. Scott (1992), Wasserman y Faust (1994), Hanneman y Riddle (2005) y Borgatti, Everett y Freeman (2002).

${ }^{6}$ Las medidas generadas son las siguientes: $n^{\circ}$ de nodos; $n^{\circ}$ de vínculos; densidad; diámetro; índice de centralización; coeficiente de aglomeración; 2-clans/nodos; 3-clans/nodos; $n^{\circ}$ de esferas; $n^{\circ}$ de contextos; E-I de esferas; E-I de contextos; tamaño eficiente; densidad de la red ego (estas dos testan los efectos de los agujeros estructurales); grado medio; información; \% de fuera; E-I de localidad.

7 Para el análisis de las asociaciones y la determinación de las dimensiones sociales involucradas se realizó un análisis factorial por componentes principales. El estudio de los dieciocho indicadores señaló la existencia de cinco factores con autovalores superiores a 1 , explicando un $73,3 \%$ de la variancia. Además de las tres dimensiones citadas (que explican respectivamente 25,6; 20,3 y 13,5\% de la variancia), aparecieron con importancia menor la estructura de la red egocentrada (medida por el tamaño eficiente de Burt) y la actividad relacional (medida por el grado medio). Esas dos dimensiones (que explican respectivamente 7,3 y $6,6 \%$ de la variancia), sin embargo, se mostraron irrelevantes en los análisis posteriores de la heterogeneidad y de los efectos de las redes sobre la pobreza, razón por la cual me concentro en las tres primeras.
} 
y 449 nodos. El grado medio (el promedio de vínculos por nodo) es poco menos de 2, el índice de aglomeración (que indica la formación de grupos cohesionados) es de 0,46 y la centralización (que indica cuan centrada en el ego está la red) es de 37\%. El diámetro medio (distancia máxima entre los nodos) es de 6,3 pasos y la densidad media (proporción de vínculos posibles observados) es de 0,104.

La presencia de conterráneos en las redes ocurre en el $8 \%$ de las redes y la homofilia de género en promedio (proporción de hombres en las redes de hombres y de mujeres en las redes de mujeres) es de $62 \%$. La presencia de personas externas a la localidad estudiada es de $37 \%$ en promedio, aunque varíe entre el $24 \%$ en Paraisópolis y el $27 \%$ en Jaguare y aproximadamente un $50 \%$ en los conventillos del área central y en Vila Nova Esperança. En este sentido, las informaciones indican mayor localismo en promedio en las localidades menos segregadas, contrariamente a lo que seria esperado si se partiese de una relación directa entre segregación y redes. Además, entre los individuos que trabajaban, el $62 \%$ lo hacían fuera de la comunidad, confirmando el hecho de que si la sociabilidad está en la localidad, las oportunidades tienden a localizarse en otros lugares.

Sólo a título de ejemplo, presento abajo el sociograma de la entrevistada 164 con características muy próximas al promedio -51 nodos, 103 vínculos, grado 2, centralización de 13\% y aglomeración de 0,50. Se trata de una habitante de Cidade Tiradentes de 46 años, emigrante, casada hace 23 años y que se encontraba desempleada en el momento de la entrevista.

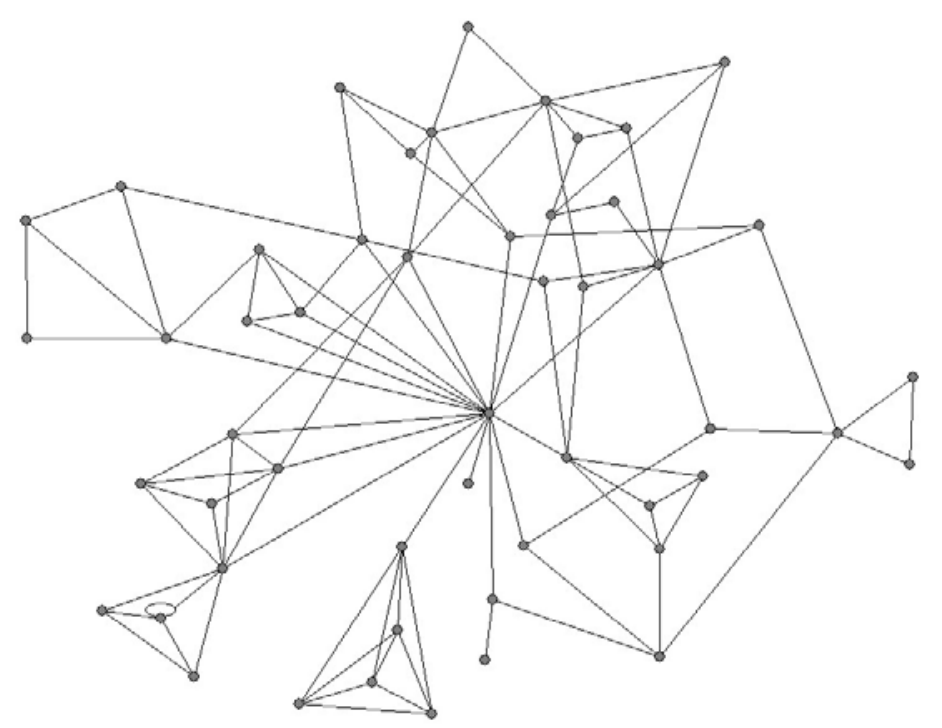

Figura 1. Sociograma de la entrevistada 164.

Fuente: Elaboración propia a partir del material empírico recogido. 
Por otro lado, los individuos de la clase media tienen redes muy distintas. Su tamaño promedio es de 94 nodos y de 183 vínculos, números sustancialmente más altos que los de los individuos en situación de pobreza, aunque la variación también fuese grande entre estos individuos - entre 26 y 239 nodos. Las redes de los individuos de la clase media tienen un diámetro promedio de 7,4 pasos y grado medio de 2 vínculos, similar a las redes encontradas en las áreas pobres. El coeficiente de aglomeración es de 0,52 y de centralización, $42 \%$. Las redes de la clase media, por lo tanto, tienden a ser mucho más grandes y ligeramente más cohesionadas ${ }^{8}$.

La figura siguiente presenta, a título de ilustración, un caso de la clase media próximo a los valores promedios referidos. Se trata del caso 93, una mujer de 38 años casada y que trabajaba en el sector administrativo de una organización de pequeño porte. Como se puede ver, en comparación a la figura anterior su red es sustancialmente más grande, más compleja y centrada en el ego.

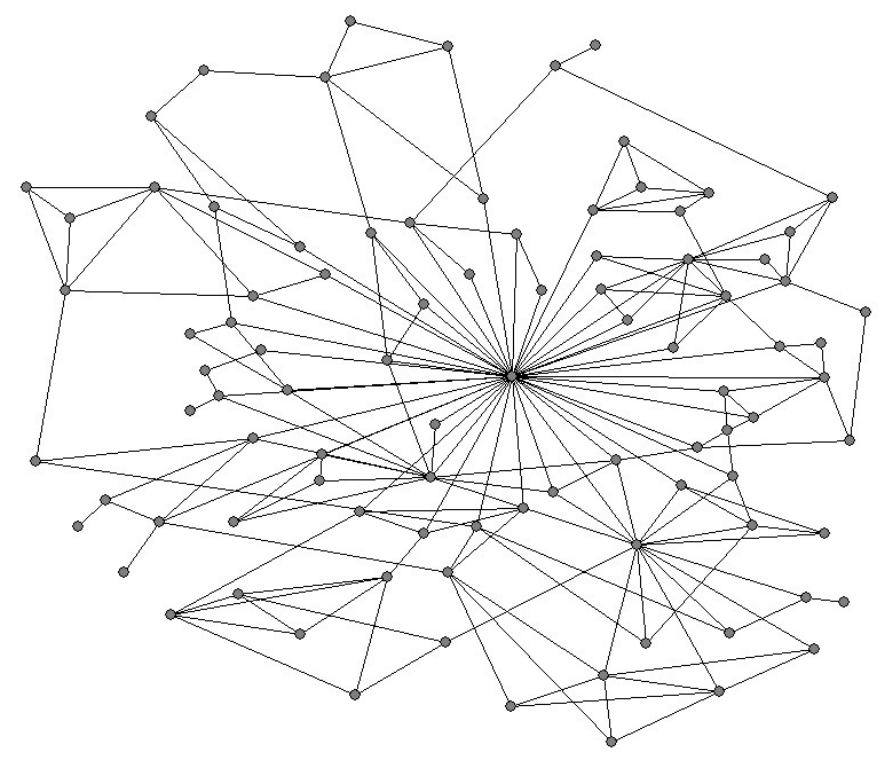

Figura 2. Sociograma de la entrevistada 93.

Fuente: Elaboración propia a partir del material empírico recogido.

\footnotetext{
8 Vale notar una dimensión importante asociada a una división entre las redes de los individuos que trabajan o no en actividades asociadas a comunidades profesionales, al contrario de lugares meramente de trabajo. Las comunidades profesionales son un tipo de esfera de sociabilidad de trabajo que incluye conjuntos de individuos y organizaciones asociadas entre si y comprometidas con determinadas prácticas e identidades profesionales ligadas a temas de actividad (Marques, 2000 y 2003). La mayor parte de las profesiones, hasta las de clase media, involucra la existencia sólo de lugares de trabajo, que son espacialmente localizados y presentan escala mucho más restricta que las comunidades. Entre los individuos que se insertan en comunidades profesionales el promedio de nodos es de 131, contra 70 entre las personas con inserción sólo en lugares de trabajo. La variabilidad de la sociabilidad (medida por el número de diferentes esferas) también es mayor para aquellos en comunidades profesionales, pero las diferencias no son significativas estadísticamente. Una posible explicación para este resultado es el hecho de que los trabajos que involucran comunidades profesionales necesitan mantener vínculos activos (o latentes) por largos períodos, superponiéndose en el tiempo como camadas cuya activación más intensa está separada en el tiempo, pero coexisten en el presente de las redes. Sólo la realización de una investigación específica permitirá especificar la importancia de este mecanismo. El fenómeno es inexistente entre los individuos en situación de pobreza.
} 
Además de ello, las redes de la clase media son básicamente asociadas a personas de fuera de la localidad del domicilio, en este caso definida como cierta región de la ciudad - cerca del $80 \%$ de los individuos presentes en estas redes vivían fuera de esta región. Su localismo, por lo tanto, es mucho menor que el de los individuos en situación de pobreza. Las redes de este estrato social corresponden a lo que Wellman (2001) denomina como comunidades personales. Por otro lado, la proporción de conterráneos es más elevada que en las redes de individuos en situación de pobreza - $11 \%$ contra el $8 \%$ entre los individuos en situación de pobreza, a pesar de que la proporción de entrevistados emigrantes es menor ( $27 \%$ contra el $70 \%$ entre los pobres), indicando la mayor permanencia de pedazos de las redes previas a la migración. La homofilia de género, por otro lado, es menos frecuente que entre los pobres -en promedio el $55 \%$ contra el $62 \%$.

Observemos ahora la sociabilidad de los individuos investigados. El número total de esferas de sociabilidad es de 3,8, variando poco entre los campos, aunque entre los individuos varíe entre uno y ocho. En términos medios, la esfera con más individuos proporcionalmente es la familia, con $40 \%$, seguida del vecindario con $32 \%$. El nivel medio de las demás esferas es mucho más bajo: $9 \%$ de individuos en la esfera trabajo, $6 \%$ en la esfera amistad, $5 \%$ en la esfera iglesia, $3 \%$ en estudios y $2 \%$ en asociaciones. La presencia de las distintas esferas en cada red varía mucho, desde la inexistencia de ciertas esferas en algunas redes hasta prácticamente la inclusión de toda la red en una única esfera.

En términos promedios, esta baja presencia de esferas esconde variaciones significativas entre los individuos, variaciones que representan una clave para comprender la especialización de las sociabilidades, más allá de las esferas familia y vecindario que aparecen como denominador común de la sociabilidad. Así, para 59 individuos, por ejemplo, la esfera trabajo incluye más que el $10 \%$ de su sociabilidad, mientras que para 29 de ellos esta esfera incluye más que el $20 \%$ de los nodos de sus redes. Para 37 individuos la esfera iglesia incluye más del $10 \%$ de su red, mientras que para diecisiete incluye más del $20 \%$. Con la esfera estudio ocurre algo parecido y sólo 28 individuos tienen participaciones mayores que el $10 \%$ en esta esfera de sociabilidad. Para veinte personas, por otro lado, la esfera ocio incluye más del $10 \%$ de los nodos. La sociabilidad en asociaciones es más estricta, y sólo catorce individuos presentan participaciones de más del $10 \%$ en esta esfera. 
El número promedio de contextos originales de los vínculos es de 4,4, variando entre dos y nueve ${ }^{9}$. Los más importantes orígenes de los vínculos fuera de la familia $(27 \%)$ son los contextos de red $(26 \%)$ y el vecindario ${ }^{10}$.

Como sería de esperar, la sociabilidad de la clase media es muy distinta a la de los entrevistados en situación de pobreza. La clase media tiene redes con un promedio de 5,5 esferas, lo que sugiere una diversificación mucho mayor de la sociabilidad en las redes de la clase media.

La proporción de individuos en la esfera familia no es muy distinta a la encontrada en las redes de individuos en situación de pobreza (35\%) pero en las demás esferas las diferencias son grandes. La esfera trabajo incluye, en promedio, el $26 \%$ de los individuos de las redes y la esfera amistad el 14\%. En un nivel más bajo, se sitúan las esferas estudios con el $10 \%$, ocio con el $6 \%$ y vecindario con el $5 \%$. Las esferas iglesia y asociaciones alcanzaban menos del $1 \%$ de los nodos de las redes. Las informaciones de las redes individualmente refuerzan el patrón, observándose que la esfera vecindario tiene valores distintos de cero en sólo el $30 \%$ de las redes, y la iglesia en sólo el $2 \%$ de los casos. La participación de la esfera trabajo, por otra parte, varía de cero hasta el $59 \%$, pero tiene valores inferiores al $10 \%$ en sólo el $20 \%$ de las redes.

Al comparar con las redes de individuos en situación de pobreza, por lo tanto, podemos decir que la sociabilidad de la clase media está más fuertemente basada en las esferas trabajo y estudios y mucho menos asociada a la esfera vecindario. La esfera familia involucra básicamente la misma proporción de la sociabilidad en ambos grupos sociales.

Los contextos de entrada también tienden a ser más variados en las redes de la clase media alcanzando, en promedio, 5,3 contextos, lo que fortalece la sugerencia de un mayor encapsulamiento de la sociabilidad de los más pobres. Los contextos más comunes son la red (44\%), seguidos de lejos por la familia con el $18,7 \%$, el trabajo con el $16,3 \%$ y los estudios con el 10,8\%. El vecindario da cuenta sólo del 3,9\%. Comparativamente, por lo tanto, las redes son mucho más importantes para la expansión de las redes de la clase media, mientras el vecindario representa un mecanismo residual, diferentemente de lo que ocurre con los individuos en situación de pobreza. Trabajo y estudios también presentan una importancia mucho mayor.

\footnotetext{
${ }^{9}$ El contexto captura la construcción de los vínculos y en qué situación una cierta persona entró en la red de un ego dado.

10 El contexto red captura la entrada de individuos en una dada red a través de otros individuos, mediante presentación.
} 
Vale recordar que, como es destacado por McPherson et al. (2001), los lugares de trabajo y de estudio representan, potencialmente, contextos que generan menor homofilia y mayor cambio social que los del vecindario y la familia. Todos estos indicadores señalan una mayor diversidad social de las redes de la clase media cuando son comparadas a las de los individuos en situación de pobreza. Estos elementos son al mismo tiempo marcadores de las diferencias entre las redes y reproductores de estas diferencias en momentos futuros.

\section{Explorando la heterogeneidad de las redes}

A pesar de las regularidades destacadas ( $y$ del promedio de las diferencias respecto a las redes de la clase media), las redes de los individuos en situación de pobreza varían mucho entre si. El mejor camino metodológico a seguir, por lo tanto, ha sido explorar exactamente la diversidad de las situaciones existentes.

Después de una serie de experimentos, llegué a la conclusión de que sería mejor producir dos tipologías distintas - una para las redes en sí, clasificadas según sus características, y otra para los patrones de sociabilidad de los individuos, clasificados según el énfasis en determinadas esferas. Mientras las primeras nos informan acerca de las estructuras de relaciones de los individuos, las segundas se refieren a los usos diferenciados de tales estructuras por los individuos en sus prácticas de sociabilidad. Aunque esta separación sea meramente analítica y metodológica (y toda red conlleve al mismo tiempo un patrón de sociabilidad), opté por separar las dos dimensiones, pues no siempre las redes y la sociabilidad co-varían, y la construcción de una única tipología tiende a enmascarar las diferencias existentes ${ }^{11}$. Posteriormente, el cruce de las dos tipologías ha definido los tipos de patrones de relación existentes en los casos estudiados. Estos patrones tienen una influencia significativa sobre la pobreza, aunque las consecuencias no sean analizadas en este artículo (Marques, 2009 y 2008). Observemos en primer lugar los tipos de redes para luego explorar las distintas sociabilidades.

\section{Los tipos de redes}

Para analizar la variabilidad de las redes utilicé los indicadores ya citados que indican el tamaño, la cohesión, la conectividad, la formación de grupos, la actividad relacional, la estructura de la red egocentrada, la variabilidad de la sociabilidad y el localismo ${ }^{12}$. Los

\footnotetext{
11 En un primer ejercicio exploratorio con sólo 89 redes (Marques et al., 2008) adopté una única tipología de atributos, indicadores de red y de sociabilidad, pero el procedimiento se reveló inadecuado para las 209 redes estudiadas aquí.

12 Fueron utilizados en el análisis: nodos; vínculos; densidad; diámetro; grado medio; centralización; coeficiente de aglomeración; índice E_I del barrio; índice E_I de los contextos; índice E_I de las esferas; no de 2-clans/no de nodos; no de 3-clans/no de nodos; intermediación; información; tamaño eficiente de
} 
casos caracterizados por estos indicadores fueron sometidos a un análisis de agrupamientos, resultando en cinco tipos de redes ${ }^{13}$. Los indicadores son presentados en la Tabla anexada al final del artículo, pero el siguiente gráfico resume las diferencias entre los tipos de redes a partir de tres dimensiones fundamentales: tamaño, localismo y variabilidad de la sociabilidad, medidos respectivamente por el número de nodos (en el primer eje de las ordenadas), por la proporción de individuos externos al área (en el segundo eje de las ordenadas) y por el número promedio de esferas de sociabilidad (indicado directamente en el gráfico).

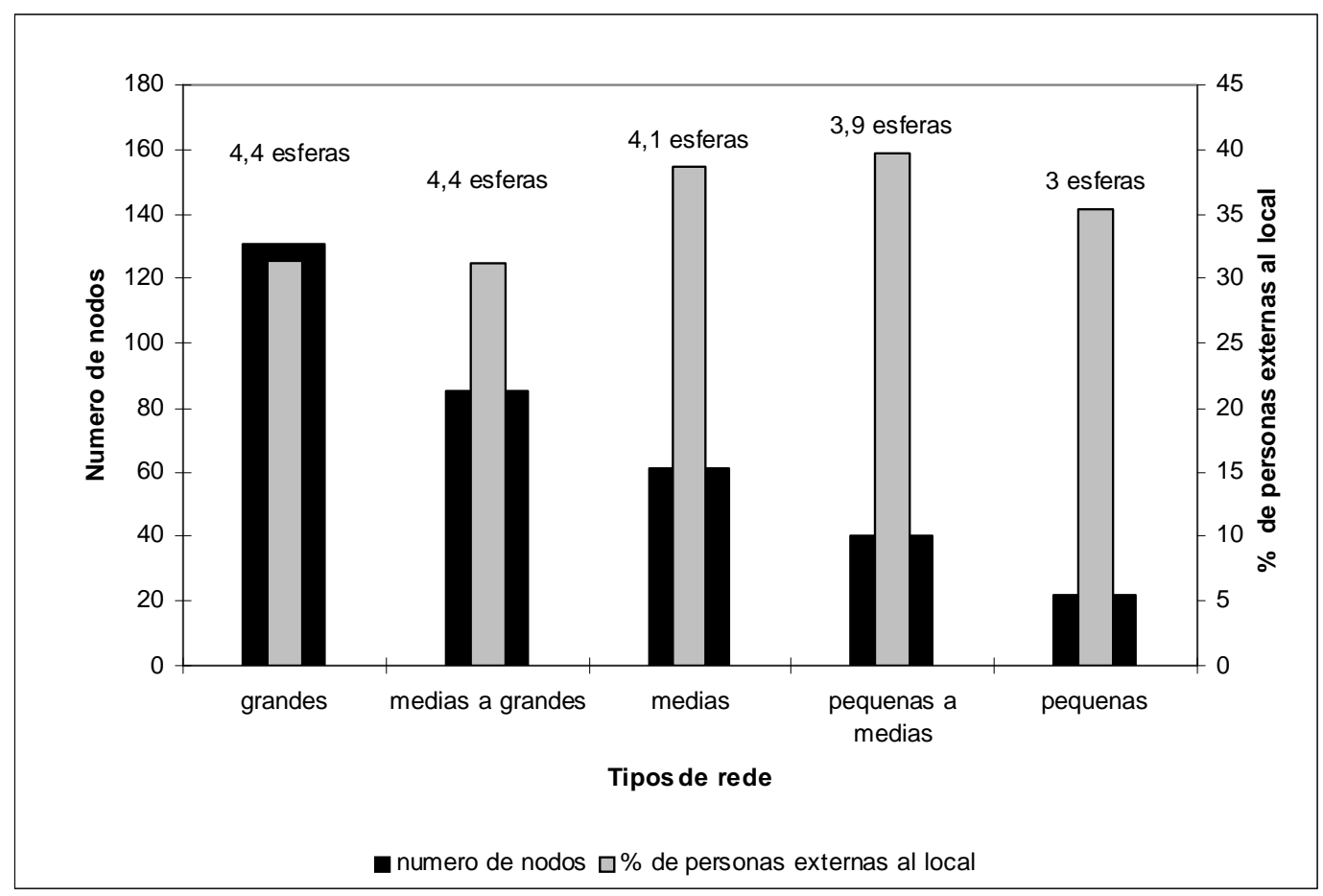

Gráfico 1. Tamaño, localismo y variabilidad de la sociabilidad por tipo de red Fuente: Elaboración propia a partir del material empírico recogido.

Vale informar que los tipos de red tienen números de casos muy distintos $-14,21$, 59, 68 y 47 casos, respectivamente. Las redes menos frecuentes son las de mayor tamaño, un resultado esperado dada la caracterización anterior de las redes de los individuos en situación de pobreza.

Como podemos ver, el tamaño de las redes y la variabilidad de la sociabilidad tienden a reducirse en la medida en que caminamos del primer al segundo grupo. El localismo, por el contrario, tiende a aumentar, aunque no de forma monotónica - las mayores redes presentan los mayores localismos, pero las menores redes también presentan un

13 El análisis utilizó el algoritmo K-means en el software Spss 13.0. 
localismo más elevado que las redes medias y las redes entre medias y pequeñas ${ }^{14}$. Las redes intermediarias conjugan tamaño medio, bajo localismo y una sociabilidad más variada.

Vale recordar que las redes de la clase media tienen un promedio de 94 nodos, cerca del $80 \%$ de los individuos de fuera de la localidad del domicilio y 5,5 distintas esferas de sociabilidad. Observemos los tipos más detalladamente, ejemplificándolos siempre sea que posible.

a) Redes grandes con sociabilidad variada, pero muy locales - 14 casos

Las redes grandes son las menos frecuentes. Su tamaño es superior al tamaño promedio de las redes de la clase media (131 nodos contra 94), pero la inserción urbana y la variabilidad de la sociabilidad son mucho menores. Los individuos con redes de este tipo tienen un ingreso promedio familiar per capita de R $\$ 235$ (el más bajo entre los grupos), edad promedio de 32 años (más joven que los demás grupos) y escolaridad alta, considerando el grupo social en estudio - 7,6 años de estudio, característica asociada a la mayor presencia de jóvenes. Los solteros y las mujeres están sobre-representados en este grupo, que presenta la menor homofilia de género entre todos los tipos. Los jóvenes y los estudiantes están sobre-representados, así como los desempleados. En general, los individuos del grupo no son emigrantes y entre los que trabajan la mayor parte lo hace en la comunidad. El grupo incluye individuos sin religión, si bien la frecuencia es superior al promedio entre los que tienen religión. Las redes grandes están sobre-representadas entre los segregados y más presentes en Cidade Tiradentes (donde entrevisté personas más jóvenes), en el Jardim Angela y en Guarulhos. Estas características deben ser consideradas con cautela dado el pequeño número de casos.

El sociograma del entrevistado 155, más abajo, ilustra estas redes. Se trata de un joven estudiante de Cidade Tiradentes con veinte años de edad y diez años de estudio. Él nació en Sao Paulo y afirma no tener religión. Su red tiene 130 nodos y 328 vínculos, seis esferas y cinco contextos distintos, pero sólo un $11 \%$ de los individuos fuera de Cidade Tirandentes ${ }^{15}$

\footnotetext{
14 De forma general, para el conjunto de los indicadores, a medida que caminamos del primero al último tipo, el tamaño, la densidad, la aglomeración, la centralización y las medidas de la red egocentrada crecen, mientras que el diámetro y la centralización decrecen. La proporción de la presencia de agrupamientos por nodo (dos y tres n-clans) tiende a acompañar el tamaño y a caer del primer al último tipo. La actividad en la red (medida por el grado y por la información), la variabilidad de la sociabilidad, así como la inserción urbana, sin embargo, no varían directamente con el tamaño y no tienen un comportamiento uniforme en cada tipo de red. Para mayores detalles, v. la tabla en anexo. ,

15 El índice de centralización es de 50\% y el grado médio de 2,53. La red incluye 51 2-clans y 42 3clans.
} 


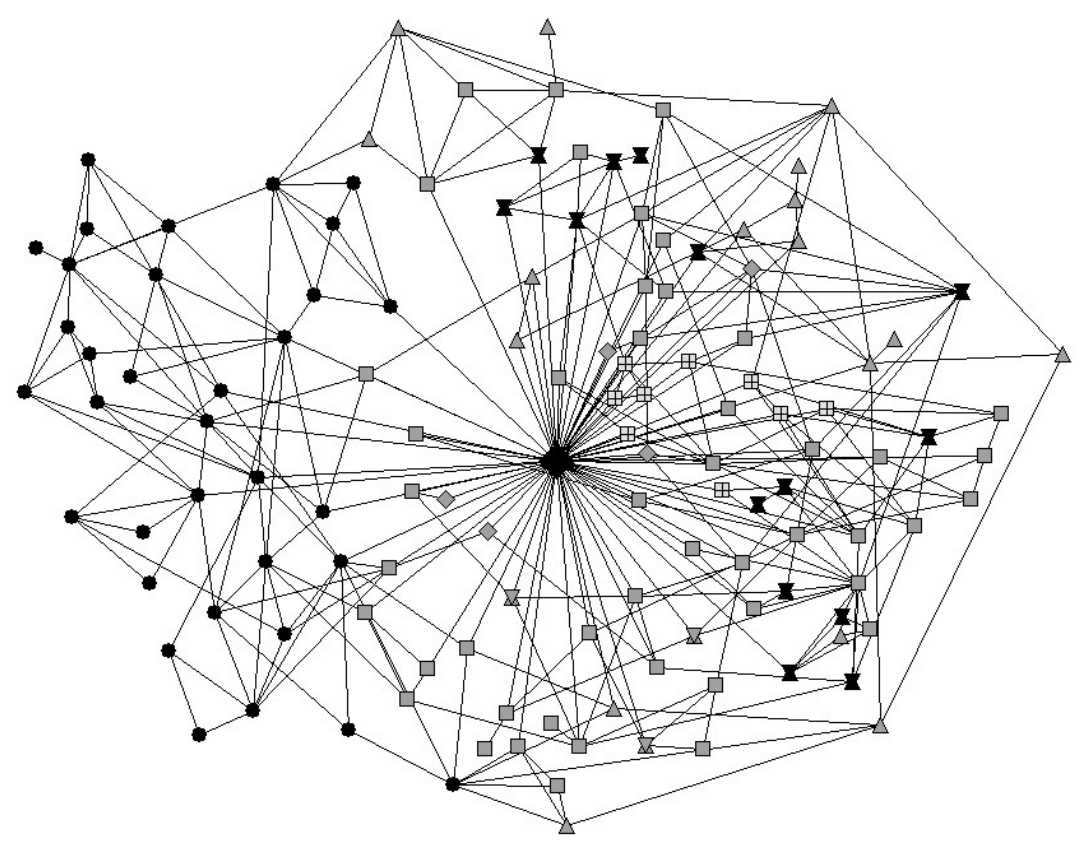

Figura 3. Sociograma del entrevistado 155.

Leyenda: Rombo grande - Ego; círculos negros - familia; cuadrados - vecindario; triángulos amistad; cuadrados claros con señal negativa - estudios; ampolletas negras - ocio y rombos oscuros - otros.

Fuente: Elaboración propia a partir del material empírico recogido.

Se trata de una red extensa y con una estructura compleja, en la cual una amplia región es ocupada por la esfera familia (a la izquierda) con pocas conexiones con el resto de la red, excepto el ego. Sus demás 5 esferas, sin embargo, se encuentran sustancialmente superpuestas. A la derecha de la red se localiza una región ocupada sobre todo por vecinos, amigos y colegas de estudio y ocio. La centralización de la red es muy alta y una gran parte de la actividad pasa por el ego, aunque varios de los agrupamientos existentes se conectan directamente entre sí.

b) Redes grandes a medias con sociabilidad muy variada y alto localismo - 21 casos

Estas redes son sólo un poco menores que las redes de la clase media ( 85 nodos contra 94) aunque el localismo sea mayor y la variabilidad de la sociabilidad menor. Las personas con redes grandes a medias presentan un ingreso promedio per capita relativamente elevado ( $R \$ 280$ ), pero con elevada variabilidad ${ }^{16}$. Estos individuos presentan en promedio una edad de 38 años y una escolaridad un poco más alta que el promedio, alrededor de 6,8 años de estudio. Aquellos que tienen compañeros están sobre-representados y la principal forma de obtención del empleo es la red. Están sobrerepresentados los individuos que trabajan en la comunidad, los que obtuvieron trabajo a

\footnotetext{
16 La desviación estándar es de $\mathrm{R} \$ 264$ y hay cuatro casos con un ingreso familiar per capita superior a $\mathrm{R} \$ 600$ y seis con un ingreso inferior a $\mathrm{R} \$ 150$.
} 
través de la red, así como los emigrantes. Los empleados con contrato de trabajo, los pequeños propietarios y los trabajadores domésticos sin contrato tienen este tipo de redes con más frecuencia. Los individuos tienden, más que el promedio, a no tener religión. Redes de este tipo son más frecuentes en Jaguare, en los conventillos y en el J ardim Angela.

El ejemplo de las redes grandes a medias es la entrevistada 47, que vive en un conventillo del área central. Se puede ver el sociograma de su red a continuación. Se trata de una mujer casada con dos hijos y sólo dos años de estudio. Es natural de Sao Paulo y trabaja como empleada doméstica sin contrato, siendo su ingreso de R\$130 per capita.

Su red tiene 97 nodos y 218 vínculos, sólo tres esferas y tres contextos y un $41 \%$ de individuos que se encuentran fuera del circuito de los conventillos ${ }^{17}$. Como se puede ver, la red es menor que la anterior, pero así mismo no presenta una estructura simple, incluso en lo que respecta a la distribución de los individuos por las esferas, las cuales se encuentran muy inter-penetradas.

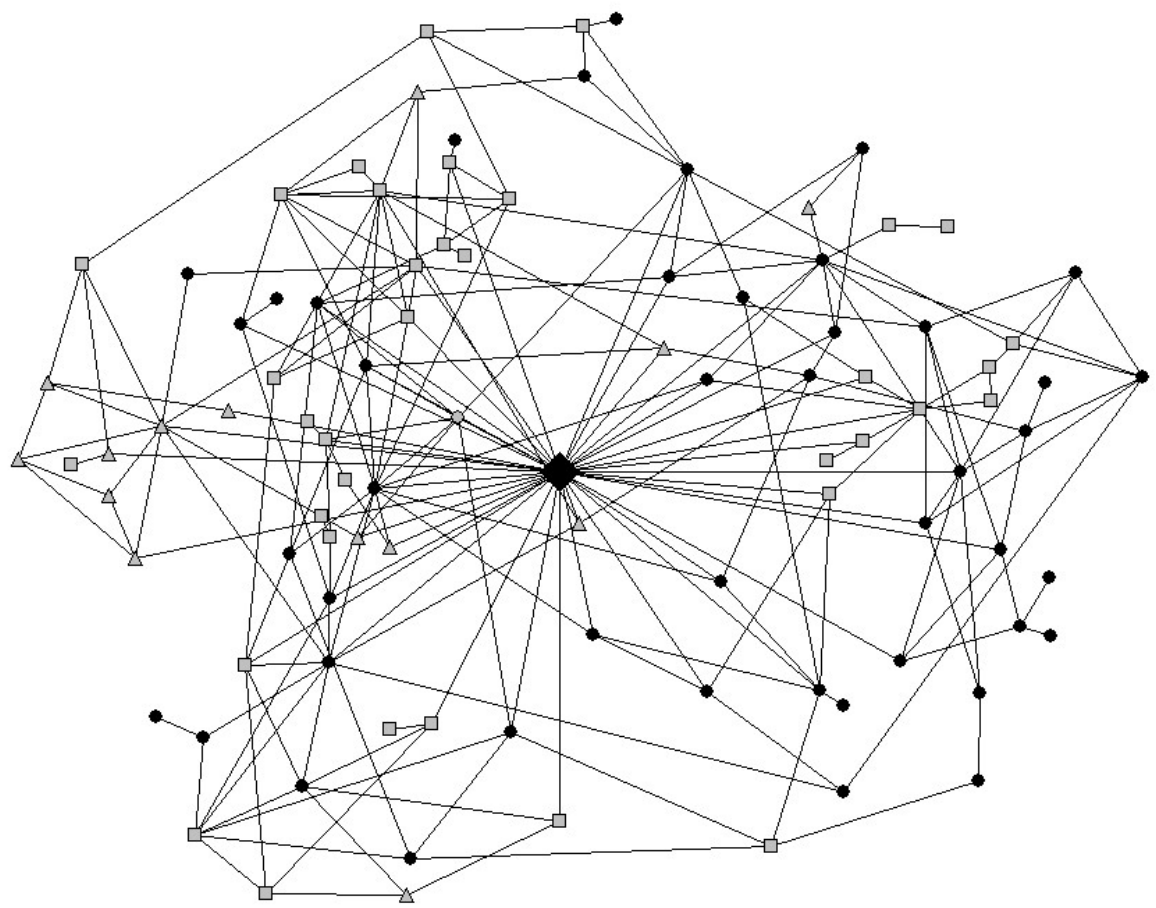

Figura 4. Sociograma de la entrevistada 47.

Leyenda: Rombo grande - Ego; círculos negros - familia; cuadrados - vecindario; triángulos - amistad. Fuente: Elaboración propia a partir del material empírico recogido.

17 La red es poco centralizada (índice de 19\%), presenta un coeficiente de aglomeración muy bajo $(0,27)$ y incluye 732 -clans y 483 -clans. 
c) Redes medias con variabilidad media de la sociabilidad y bajo localismo - 59 casos

Las redes de este tipo pertenecen a personas con ingreso familiar per capita y características semejantes al promedio del grupo estudiado - R\$265, edad de 35 años y escolaridad de 6,1 años de estudio (contra R\$270, 36 años y 6,1 años de estudio para el conjunto de las redes). Individuos con redes de este tipo tienen empleos obtenidos a través de la red más frecuentemente que los demás y el tamaño promedio relativo de los domicilios tiende a ser más alto. Estas redes son más frecuentes en los conventillos y en Vila Nova Esperança.

El ejemplo de este tipo de red se presenta en el sociodrama de más abajo, perteneciente a la entrevista 60 . Se trata de una mujer de 38 años migrada de Bahía hace más de cinco años y habitante de Vila Nova Esperança. Ella trabaja como limpiadora a jornal en casas de familia sin contrato de trabajo, tiene ocho años de escolaridad y su ingreso per capita es de $R \$ 150$. La red tiene 53 nodos y 119 vínculos, un $43 \%$ de individuos externos, y seis esferas y contextos de sociabilidad.

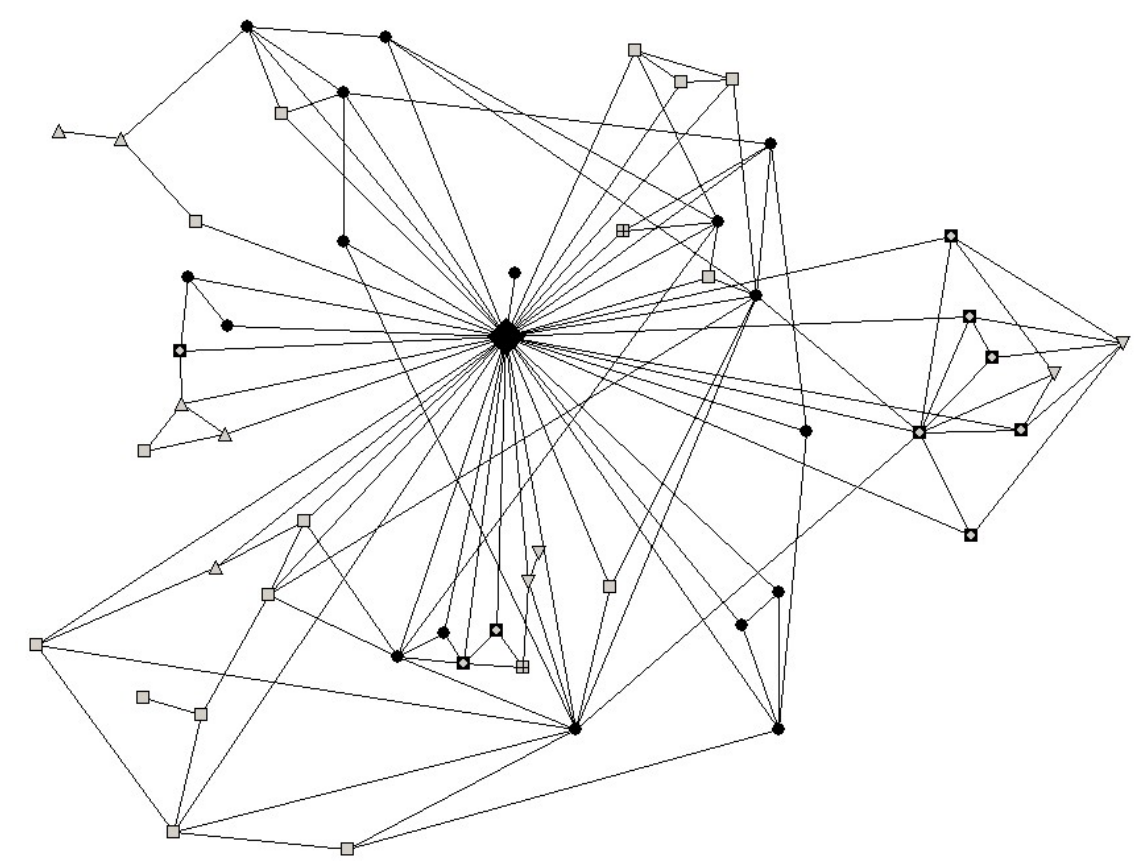

Figura 5. Sociograma de la entrevistada 60.

Leyenda: Rombo negro - Ego; círculos negros - família; cuadrados - vecindario; triángulos asociativismo; cuadrados com rombos - amistad; cuadrados con señal positiva - estudios; triángulos invertidos - trabajo.

Fuente: Elaboración propia a partir del material empírico recogido. 
La red es aun menor y más simple que la anterior. Su estructura es un poco más visible, con un grupo de amistad y de trabajo a la derecha y otro de esferas mixtas a la izquierda. Sin embargo, la más fuerte diferencia de esta red respecto a las anteriores es su elevada centralización (índice de centralización de 73\%), o sea, el hecho de que muchos vínculos pasan por el ego ${ }^{18}$. La cantidad de esferas distintas de sociabilidad (seis) también es más elevada en esta red que en la anterior.

d) Redes medias a pequeñas con variabilidad media de la sociabilidad y bajo localismo 68 casos

Este tipo de red es el más frecuente y muy próximo al promedio de los indicadores en general. Los individuos con redes medias a pequeñas tienen un ingreso promedio familiar per capita superior al promedio ( $R \$ 290$ ), 34 años de edad y 6,2 años de estudio. El promedio de la homofilia de sexo es el más alto entre los tipos de red. Los individuos con este tipo de red tienden a ser más frecuentemente doñas de casa, empleados con contrato, y autónomos. Hay algunas personas mayores, pero también individuos muy jóvenes. Este tipo está bien distribuido entre los campos, pero está levemente sobre-representado en Guarulhos y Vila Nova Esperanza. Los evangélicos están sobre-representados en este tipo de red. El localismo es el más bajo entre todos los grupos.

El ejemplo de este tipo de red es el entrevistado 52, un habitante de los conventillos nacido en Bahía, joven (19 años), casado y con dos hijos. Trabaja como ayudante en un estacionamiento (con contrato de trabajo) y tiene un ingreso per capita de $R \$ 115$. Él tiene cinco años de estudio y se considera evangélico, aunque afirme nunca frecuentar templos. Su red tiene 37 nodos y 91 vínculos, y cinco esferas y contextos. Casi el $62 \%$ de los individuos de su red son externos al circuito de los conventillos ${ }^{19}$. El sociograma se presenta a continuación.

\footnotetext{
18 A pesar de que la aglomeración es relativamente alta - 0,53 - no hay muchos agrupamientos cohesionados - once 2 -clans y ocho 3 -clans (contra 73 y 48 , respectivamente, en el último tipo de red). 19 La centralización y la aglomeración son altas - 70\% y 0,63. La red presenta solo siete 2-clans y cuatro 3-clans.
} 


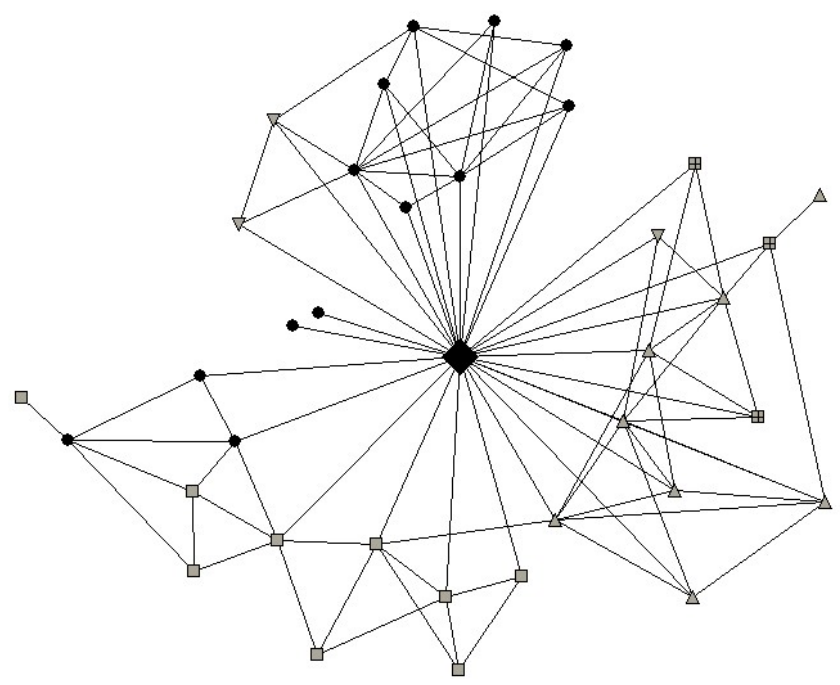

Figura 6. Sociograma de entrevistado 52.

Leyenda: Rombo negro - Ego; círculos negros - familia; cuadrados - vecindario; triángulos - trabajo; cuadrados con señal positiva - ocio, triángulos invertidos - otros.

Fuente: Elaboración propia a partir del material empírico recogido.

La red presenta una estructura simple y muy centralizada en torno del ego. Su regionalización según esferas de sociabilidad es nítida, con la familia arriba, el vecindario a la izquierda y abajo, y las esferas trabajo y ocio inter-penetradas abajo a la derecha.

e) Redes pequeñas con baja variabilidad de la sociabilidad y alto localismo - 47 casos

Las redes pequeñas, por fin, son características de individuos con una edad promedio relativamente más elevada -41 años (son, en promedio, los individuos más mayores) y escolaridad más baja (5,2 años de estudio). A pesar de ello, el grupo incluye un conjunto no despreciable de individuos muy jóvenes, comprobando nuevamente la relación no directa entre atributos y redes. El ingreso familiar per capita - R\$ 255- no es, en promedio, el más bajo, pero la desviación estándar del grupo es la más elevada (R\$ 260), lo que sugiere una gran variabilidad de los ingresos ${ }^{20}$. Los individuos emigrantes están sobre-representados en este grupo y la mitad de los que tienen muchos coterráneos (más del 20\%) en sus redes tienen redes pequeñas. Es el tipo donde se encuentra la mayor incidencia de personas sin religión, pero también de católicos, aunque la frecuencia de visitas a templos evangélicos sea la menor entre todos los grupos. Doñas de casa y autónomos sobresalen, aunque ligeramente. Este es el tipo de

\footnotetext{
20 Efectivamente, dentro de este grupo se encuentra un individuo con un ingreso mucho más elevado que los demás. Si este fuese excluido, el ingreso medio resultaría $\mathrm{R} \$ 225$, el menor entre todos los tipos de rede.
} 
red menos incidente en localidades segregadas, estando sobre-representados los que habitan en Paraisópolis.

El ejemplo en este caso es la entrevistada 142, habitante de Paraisópolis. Se trata de una mujer de 64 años nacida en Bahía, sin compañero y que vive sola. Es analfabeta, no trabaja y se autodenomina católica, aunque prácticamente nunca frecuenta la iglesia. Trabajó como empleada doméstica, pero nunca tuvo contrato y, aunque actualmente no trabaja, no ha obtenido aún la jubilación. Vive en una vivienda muy precaria y no tiene ingresos. Su sociograma se presenta a continuación.

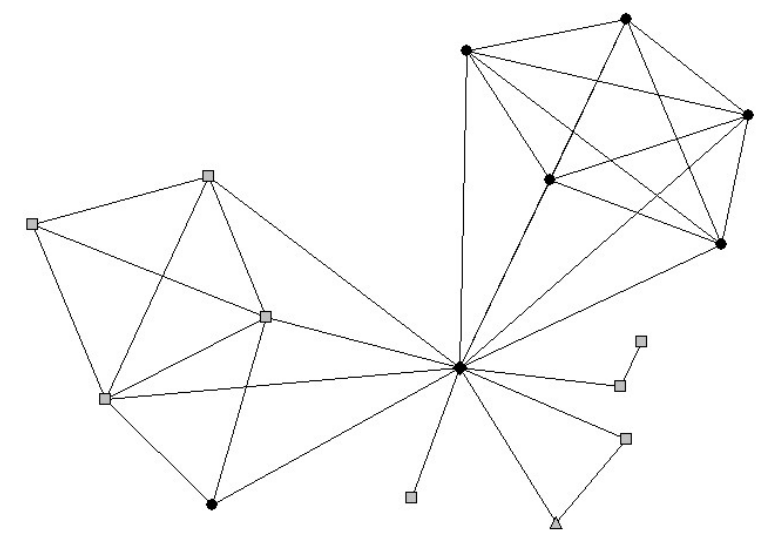

Figura 7. Sociograma de la entrevistada 142.

Leyenda: Rombo negro - Ego; círculos negros - familia; cuadrados - vecindario y triángulo - amistad. Fuente: Elaboración propia a partir del material empírico recogido.

Su red tiene sólo dieciséis nodos y 33 vínculos, tres esferas y cuatro contextos ${ }^{21}$. La red es pequeña y extremamente simple. Arriba y a la derecha del ego se sitúa un grupo de la esfera familia completamente conectado, y a la izquierda y abajo otros dos grupos basados en el vecindario que también se presentan muy conectados.

¿Pero cómo los tipos de redes se distribuyen en las localidades estudiadas? La existencia de regularidades tal vez señale posibles efectos directos de la segregación sobre las redes. Esa incidencia en los campos, sin embargo, sugiere la inexistencia de patrones nítidos y robustos, ya sea por la localidad estudiada o según grados de segregación.

\footnotetext{
21 En gran parte como efecto del tamaño, la rede es altamente aglomerizada $(0,59)$ y centralizada $(67 \%)$, pero incluye sólo tres 2 -clans y dos 3-clans.
} 


\section{Los tipos de sociabilidad}

Exploro ahora los escenarios de sociabilidad presentes en las redes. Para explorar esta dimensión sometí las proporciones de individuos de las varias esferas de sociabilidad a un análisis de agrupamientos ${ }^{22}$. El resultado que mejor se ajustó a los datos incluye seis tipos de sociabilidad distintos según la concentración de la sociabilidad por esferas. La tabla siguiente presenta las proporciones en promedio de las esferas para cada grupo, así como los respectivos números de casos. Las esferas destacadas concentran entre el 81 y el $90 \%$ de los tipos de sociabilidad. La última línea presenta el número de casos y la última columna presenta el promedio de la sociabilidad del grupo de la clase media, que no fue utilizada en el análisis de agrupamientos, sino que es utilizada como parámetro de comparación.

Los dos primeros tipos de sociabilidad se basan principalmente en la familia y en el vecindario - vínculos primarios y/o locales- aunque con énfasis invertidos. En el tercer tipo tenemos una gran concentración de personas en la esfera amistades, que puede o no ser local, pero que también tiende a ser marcada por la homofilia. Los demás tipos de sociabilidad se caracterizan por la presencia expresiva de relaciones construidas en ambientes institucionales o organizacionales -iglesia, trabajo y asociaciones.

\begin{tabular}{|c|c|c|c|c|c|c|c|}
\hline \multirow[b]{2}{*}{ Esferas } & \multicolumn{6}{|c|}{ Tipos de sociabilidad (\% ) } & \multirow{2}{*}{$\begin{array}{c}\text { Clase } \\
\text { media (\%) }\end{array}$} \\
\hline & familia & vecindario & amistad & iglesia & trabajo & asociación & \\
\hline familia & 63 & 28 & 33 & 27 & 27 & 32 & 34 \\
\hline vecindario & 19 & 53 & 24 & 27 & 24 & 13 & \\
\hline amistad & & & 33 & & & & 14 \\
\hline trabajo & & & & & 33 & & 26 \\
\hline iglesia & & & & 33 & & & \\
\hline asociación & & & & & & 34 & \\
\hline \multicolumn{8}{|l|}{ Ócio } \\
\hline estudios & & & & & & & 10 \\
\hline \multicolumn{8}{|l|}{ otros } \\
\hline № de casos & 67 & 67 & 16 & 20 & 33 & 6 & 30 \\
\hline
\end{tabular}

Tabla 1. Tipos de sociabilidad por esferas de sociabilidad ${ }^{(1)}$

Fuente: Elaboración propia a partir del material empírico recogido.

1. Fueron ocultadas los porcentajes iguales o inferiores al $6 \%$. Las células con fondo gris más oscuro tienen proporciones arriba del promedio y las células con fondo gris más claro tienen sociabilidades importantes para el grupo, aunque inferiores al promedio.

Es razonable considerar que las sociabilidades basadas en esferas más organizacionales lleven a patrones de contactos con menor homofilia y mayor heterogeneidad, pues los contactos construidos en estos ambientes tienden potencialmente a ser más fuertemente basados en elecciones que los contactos familiares, de vecindario y de

\footnotetext{
22 El análisis de agrupamientos incluyó todas las nueve esferas consideradas y utilizó el algoritmo K-
} means del Software Spss 13.0. 
amistad. El análisis cuantitativo de las consecuencias de las redes realizado en Marques (2009 y 2008) comprobó ampliamente esta hipótesis.

La sociabilidad de la clase media se concentra principalmente en las esferas de amistad, de trabajo y de estudios. La presencia del vecindario en las redes de clase media es muy baja, siendo hasta inferior al grupo de las redes de pobres con menor presencia de esta esfera. La presencia relativa de la esfera familia es similar al promedio de las redes de individuos en situación de pobreza.

Observemos más detenidamente los tipos de sociabilidad de los individuos, incluyendo ejemplos de los casos estudiados para concretar las situaciones delimitadas. En cada tipo destaco sólo las esferas superiores al promedio que en última instancia caracterizan cada tipo.

a) Sociabilidad caracterizada por el énfasis en la familia - 67 individuos

Los individuos cuya sociabilidad tiene énfasis en la familia tienen en promedio 38 años, una escolaridad muy baja ( 5 años de estudio) y un ingreso familiar per capita relativamente bajo $-\mathrm{R} \$ 245$. El grupo incluye un conjunto expresivo de personas mayores, es ligeramente más femenino y los individuos son mayoritariamente emigrantes. La presencia de coterráneos en las redes es la más elevada entre los tipos de sociabilidad. Las doñas de casa y los autónomos son los grupos ocupacionales que más destacan. Los individuos tienden a trabajar en la comunidad y a no frecuentar asociaciones. La mayor parte de los individuos es católica, pero no frecuenta templos regularmente. Este tipo se encuentra presente con más frecuencia en Paraisópolis, en los conventillos y en el Jardim Angela. Contiene el menor número promedio de esferas de sociabilidad entre todos los grupos.

El ejemplo de este tipo de sociabilidad es la entrevistada 133, una emigrante de Bahía de 62 años de edad. La entrevistada vive en Sao Paulo hace veinte años. Antes de irse a Paraisópolis vivía en las inmediaciones de Aguas Espraiadas, pero así que empezó la obra de la avenida se fue a vivir a Paraisópolis - hace ya más de diez años. Ella se casó en 1961 con un hombre que conoció en su ciudad natal y con quien tuvo ocho hijos. Cuando vino a Sao Paulo ya estaba separada.

Actualmente, ella vive con uno de sus hijos, mientras que una de sus hijas vive en el segundo andar de su casa. Hace cinco años que tiene un pequeño comercio en su propia casa, pero anteriormente trabajó como doméstica. Ella no estudió porque su marido se lo prohibió. El ingreso familiar es compuesto por los ingresos del pequeño comercio y por los trabajos temporarios sin contrato de su hijo, lo que corresponde a aproximadamente $\mathrm{R} \$ 300$ per capita. Ella tiene dos hermanos que viven en Bahía con 
los cuales apenas tiene contacto. Sus contactos frecuentes son con los vecinos que viven al lado y delante de su casa. A pesar de autodenominarse católica, dice que nunca va a la iglesia (desde que vive en el barrio sólo fue una vez). Ella no posee una esfera de ocio, y dijo que en sus momentos libres se queda en casa viendo la tele. Sus esferas más importantes son familia $(53,3 \%)$ y vecindario $(40 \%)$, y sólo el $20 \%$ de los nodos eran externos a la comunidad.

b) Sociabilidad caracterizada por el énfasis en el vecindario - 67 individuos

Estos individuos tienen en promedio una escolaridad de seis años de estudio, 34 años de edad y un ingreso muy bajo, $\mathrm{R} \$ 210$. En realidad, este es el grupo que presenta la mayor proporción de individuos paupérrimos y también incluye individuos emigrantes por sobre el promedio. Las trayectorias reportadas en las entrevistas indican la existencia de varios individuos que migraron diversas veces entre Sao Paulo y sus ciudades de origen. Los individuos de este grupo no frecuentan asociaciones y una parte expresiva de ellos no tiene compañero. La presencia de precariedad familiar es mayor que el promedio, así como la precariedad laboral y de ingresos ${ }^{23}$. La mayor parte de los individuos considerados precarios pertenece a este tipo de sociabilidad.

La sociabilidad de este tipo es ejemplificada por el entrevistado 9. Se trata de un habitante de Jaguare de 34 años. El entrevistado llegó a Sao Paulo hace ocho años con su esposa, ambos provenientes de una pequeña ciudad en Alagoas donde nació y donde aún sigue viviendo la mayor parte de su familia. Hace seis meses abrió una tienda de variedades en Jaguare (donde vende juguetes, CDs, caramelos, etc.) en la parte delantera de su casa, donde vive con su esposa y sus dos hijos. Anteriormente trabajó como limpiador y como camarero. Declaró un ingreso familiar mensual de $R \$ 700$, siendo que su mujer no trabaja. Manifestó ser católico, pero no practicante, y llegó a concluir el quinto año de la enseñanza fundamental.

Para divertirse el entrevistado visita la casa de parientes que viven cerca y va a una casa de espectáculos frecuentada por los emigrantes del Nordeste en el barrio de Limao, además de visitar amigos coterráneos en otros barrios. Sus principales esferas son vecindario $(41,3 \%)$ y familia $(40 \%)$, y el $28 \%$ de los nodos de su red son externos a la comunidad.

c) Sociabilidad caracterizada por el énfasis en la amistad - 16 individuos

\footnotetext{
23 Han sido considerados cuatro tipos de precariedad: la precariedad familiar implica la existencia de niños con menos de 12 años y un único proveedor adulto; la precariedad de ingreso es la presencia de un ingreso familiar per capita inferior a R\$ 120; la precariedad laboral es la existencia de desempleo o vivir de trabajos temporarios sin contrato $y$, por fin, la precariedad habitacional implica vivir en viviendas hechas de materiales precarios o viviendas sin baño.
} 
Los individuos con este patrón de sociabilidad tienen la segunda escolaridad más elevada entre todos los grupos (7,4 años de estudio), y también el más bajo ingreso promedio familiar per cápita ( $R \$ 188$ ). Este grupo tiene la edad promedio más baja - 31 años- y presenta la más elevada presencia de jóvenes. Concordante con esta característica, es el único tipo de sociabilidad más presente entre los naturales de Sao Paulo que entre los emigrantes. Se trata de un tipo muy común entre los pobres, pero no los paupérrimos, y tiende a ser ligeramente más femenino que masculino. Los estudiantes y las doñas de casa se encuentran sobre-representados. La concentración en la esfera amistad es un poco más elevada que la verificada en la clase media - el doble.

Como ejemplo de este grupo presento la sociabilidad de la entrevistada 140, una mujer de 37 años nacida en Sao Paulo y que vive en Paraisópolis. Trabaja hace un mes como auxiliar de "servicios generales" (limpieza) en la asociación de vecinos, sin contrato de trabajo, ganando $\mathrm{R} \$ 350$ al mes, y fue indicada por su madre que es una de las directoras. La entrevistada se separó de su marido y vive con sus padres, sus dos hijos y un hermano. Completó la enseñanza media y trabajó durante un año y nueve meses en una empresa prestadora de servicios de limpieza, de la que fue despedida hace tres meses. Su familia reside hace diez años en el Grotao, una de las peores áreas del asentamiento precario, y sus relaciones son predominantemente posteriores a la llegada al barrio, manteniendo pocos contactos externos con las amigas de su antiguo trabajo. Sólo $30 \%$ de los nodos de su rede son externos al barrio y sus esferas más relevantes son familia $(41,8 \%)$, amistad $(36,4 \%)$ y vecindario $(12,7 \%)$.

d) Sociabilidad caracterizada por el énfasis en las iglesias - 20 individuos

Las personas de este grupo tienen escolaridad media (6,8 años), edad de 38 años e ingreso familiar per cápita entre medio y bajo R\$275. El grupo incluye más emigrantes que el promedio del universo, pero prácticamente no incluye coterráneos $(3,7 \%)$, lo que sugiere una disolución de vínculos más elevada que el promedio. Las mujeres están más presentes aquí que en cualquier otro tipo. Los empleados con y sin contrato de trabajo están sobre-representados y la proporción de individuos que obtuvieron su empleo a través de anuncios es la mayor entre todos los casos estudiados. Las redes incluyen mucho más individuos externos a la localidad de residencia que el promedio. Naturalmente, los que frecuentan la iglesia están muy sobre-representado en este grupo y esta es la única sociabilidad donde los evangélicos son predominantes (64\%). Los individuos con esta sociabilidad tienen tanto precariedad familiar como ingresos con niveles superiores a los demás grupos. Los números de esferas y contextos son elevados $-4,3$ y 4,9 , respectivamente. 
Ejemplifico este grupo con el caso de la entrevistada 164, de Cidade Tiradentes. Se trata de una alagoana de 43 años que llegó hace 22 años a Sao Paulo. Hace catorce años que vive en Cidade Tiradentes, y antes vivió en el barrio Liberdade, en el Centro, en la casa de una cuñada. Es casada, tiene tres hijos, y vive con el marido y uno de sus hijos. Los demás hijos viven en conjuntos habitacionales vecinos y sus hermanos viven en otras localidades. Dice que es dueña de casa, pero se considera desempleada y está buscando trabajo "en lo que aparezca". Trabajó anteriormente durante 10 años como empleada domestica, sin contrato de trabajo, y durante cuatro años como camarera en un hotel de alto patrón con contrato de trabajo. El ingreso familiar es de $\mathrm{R} \$ 900$, lo que resulta en un ingreso familiar per cápita de $\mathrm{R} \$ 300$.

Es evangélica y frecuenta la I glesia Assembleia de Deus cinco veces por semana. Su ocio se resume en buscar el nieto en la casa de un hijo y en ir a la iglesia, donde tiene varios amigos. Las esferas más relevantes eran la familia $(41,2 \%)$, el vecindario $(3,9 \%)$ y la iglesia $(52,9 \%)$, siendo el $29,4 \%$ de los nodos externos a la comunidad.

e) Sociabilidad caracterizada por el énfasis en trabajo - 33 individuos

Los individuos con esta sociabilidad tienden a tener una escolaridad alta para el grupo social estudiado, alcanzando los siete años de estudio, una edad media promedio de 38 años (con muy pocos jóvenes y mayores), así como un ingreso promedio familiar per cápita alto para el grupo social estudiado -en promedio $\mathrm{R} \$ 455$. El grupo concentra especialmente individuos empleados con contrato de trabajo (52\% con contrato contra un promedio general de $16 \%$ ) en empleos relativamente antiguos y que trabajan fuera de la comunidad (73\%). En este grupo, los empleos fueron obtenidos a través de la red en una proporción mucho más elevada que la de los demás tipos de sociabilidad (95\%). Las redes incluyen muchos más individuos externos a la localidad de residencia que el promedio $(49 \%)$ y tienen menos emigrantes y mucho menos coterráneos que el promedio (sólo el $1 \%$ ), a pesar de que el $61 \%$ de los individuos son emigrantes. Los individuos que frecuentan asociaciones están sobre-representados en este grupo y los números de esferas de sociabilidad y contextos son elevados $-4,4$ y $4,8-$ respectivamente. En este caso, la proporción de la sociabilidad en la esfera trabajo es incluso superior al promedio de las redes de la clase media.

El entrevistado 70, habitante de Vila Nova Esperança, es el ejemplo de este grupo. Tiene sesenta años y nació en el interior de Sao Paulo, en la zona rural, de padres campesinos. Él migró para Sao Paulo con sólo diez años, acompañado de su madre. Tuvo seis hermanos ( 4 mujeres y dos hombres) y todos viven en barrios próximos a Sao Paulo. Está separado hace diez años y tiene dos hijos, ambos casados, siendo que uno de ellos ya tuvo dos hijos. Conoció su ex-mujer en la casa de un hermano. Vino del 
barrio vecino para la comunidad hace ocho años y compró su casa directamente de uno de los ocupantes originales. Hoy vive sólo.

Hace dos años que trabaja como vendedor autónomo de escobas para una fábrica que se localiza en Santo Amaro. Sin embargo, raramente va hasta la fábrica y hace los pedidos por teléfono. Antes trabajó para otra empresa de la misma manera durante dieciséis años, y antes fue portero de edificios durante 15 años y también metalúrgicos. Tiene un ingreso mensual de $\mathrm{R} \$ 450$ y completó la enseñanza secundaria. Su sociabilidad es organizada por las esferas familia $(41,1 \%)$, vecindario $(31,2 \%)$, trabajo $(17,7 \%)$ y tiene un $56,9 \%$ de nodos externos a la comunidad en su red, siendo esta una de las redes con más bajo localismo encontradas entre individuos en situación de pobreza.

f) Sociabilidad caracterizada por el énfasis en las asociaciones - 6 casos

Sólo seis individuos comparten este tipo de sociabilidad. Su escolaridad promedio es la más elevada de todos los grupos - 8,3 años- superando incluso la enseñaza fundamental completa. Los ingresos promedios familiares per cápita tampoco son bajos y alcanzan R\$ 440 en promedio. Las redes de los individuos con esta sociabilidad son las únicas con homofilia de género muy abajo del promedio ( $55 \%$ ). La presencia de coterráneos en las redes es muy baja (3\%). Todos los individuos trabajan en la comunidad y el localismo es el más alto de todos los tipos (sólo un $25 \%$ de los individuos son de fuera). Evidentemente, los que frecuentan asociaciones están sobre-representados entre los individuos con esta sociabilidad. Una parte importante de estos individuos está efectivamente involucrada con el asociacionismo en sus actividades cotidianas.

El ejemplo de este tipo de sociabilidad es el entrevistado 131, habitante de Paraisópolis, con 39 años y nacido en Recife. Su padre vino antes y él vino después con los demás familiares hace 36 años. Sus padres ya fallecieron y el entrevistado tiene dos hermanas vivas que no viven en el asentamiento informal. Él es casado hace trece años y tiene dos hijos. Completó la enseñanza secundaria y es uno de los directores de una de las asociaciones de vecinos del asentamiento. Además de ello, es peluquero y hace 21 años tiene su propio salón de peluquería en el barrio. Su esposa trabaja como empleada domestica en el barrio de Morumbi. El ingreso familiar es de $\mathrm{R} \$ 1.500$ y resulta un ingreso per cápita de $\mathrm{R} \$ 375$. Ya trabajó en el estadio del Morumbi cuidando de coches, como empleado en una casa de familia en Morumbi y en el salón de peluquería de un amigo de su padre. En seguida hizo un curso de peluquero en un colegio particular de la región y abrió su propio salón. Es evangélico y frecuenta la iglesia todos los días con la familia. 
Las esferas más importantes de su red son la familia $(38,7 \% 0)$ y la asociativa $(27,8 \%)$, seguidas de trabajo e iglesia con 10,7 y 16\%, respectivamente. Este individuo tiene sólo un $12,9 \%$ de contactos externos.

¿Pero de qué forma los distintos tipos de sociabilidad inciden sobre las localidades estudiadas? Una evidencia en esta dirección es una información importante para que evaluemos la relación entre la segregación social en el espacio y las redes. La distribución de los tipos de sociabilidad por las áreas se presenta en el siguiente Gráfico.

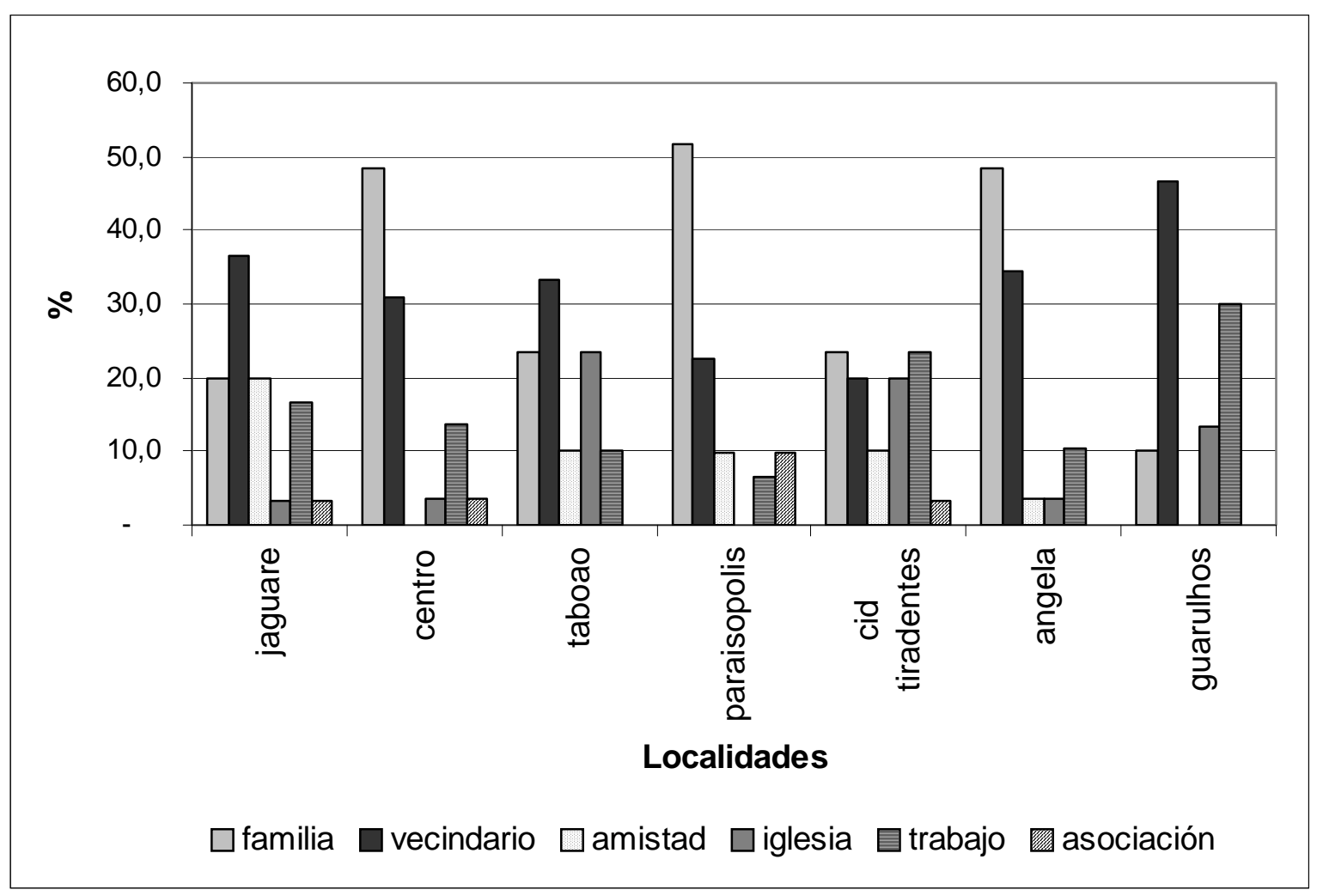

Gráfico 2. Presencia relativa de los grupos de sociabilidad en las localidades (\%) Fuente: Cálculo propio a partir del material empírico recogido.

Como se puede ver, los individuos cuya sociabilidad se caracteriza por el énfasis en la familia están sobre-representados en Paraisópolis, en los conventillos y en Jardim Angela. La sociabilidad con énfasis en el vecindario está mucho más presente en Guarulhos y la mayor concentración en la amistad ocurre en Jaguare y también en menor proporción en Vila Nova Esperança, en Paraisopolis y en Tiradentes. Las sociabilidades más primarias, por tanto, se concentran en Jardim Angela, en Paraisopolis, en los conventillos y en Jaguare. 
La sociabilidad concentrada en la esfera iglesia ocurre más intensamente en Vila Nova Esperança, Cidade Tiradentes y Guarulhos, mientras que la concentrada en ambientes de trabajo ocurre en Guarulhos y Cidade Tiradentes. La sociabilidad centrada en asociaciones, por fin, se hace más presente en Paraisópolis. Los tipos de sociabilidad menos locales, menos primarios y más asociados a ambientes institucionales y organizaciones, por lo tanto, están sobre-representados en Tiradentes y Vila Nova Esperança.

Así, aunque no existen patrones de distribución por área, hay cierta concentración de las sociabilidades menos locales y primarias en localidades más segregadas (Guarulhos, Cidade Tiradentes y Vila Nova esperanza), lo que es contrario a la hipótesis corriente sobre la relación entre redes y segregación. Este resultado corresponde a la evidencia de que los individuos segregados tienen en promedio patrones un poco menos localistas y refuerza la idea de que ciertos individuos segregados combatirían los efectos de la segregación con vínculos menos homófilos y menos locales.

\section{Combinando tipos de redes y de sociabilidad}

Después de analizar la variabilidad de las redes y de las sociabilidades, podemos investigar la existencia de combinaciones entre ellas. De forma general, la distribución de los tipos de sociabilidad por el tipo de red indica la inexistencia de asociaciones directas. Sin embargo, cuatro situaciones de individuos aparecen con mayor incidencia en los $\operatorname{casos}^{24}$ :

- con redes grandes, pero sociabilidad local y primaria (11\%);

- con redes pequeñas y sociabilidad local y primaria (17\%);

- con redes medias y sociabilidad local y primaria (44\%);

- con redes medias y sociabilidad poco local y construida en ambientes organizacionales e institucionales (15\%).

Podemos imaginar que las dos primeras situaciones relacionales tienden a favorecer potencialmente la homofilia, mientras que la última tiende a aumentar la heterofilia de los patrones de relación de los individuos. Si las hipótesis respecto a la vinculación entre heterofilia en las redes y condiciones sociales son correctas, las dos primeras situaciones tienden a asociarse a peores condiciones de vida, mientras que la cuarta situación favorecen el acceso a estructuras de oportunidad. Estas hipótesis son confirmadas de manera preliminar por la observación de las características sociales de los entrevistados en cada tipo de situación relacional.

24 Otros 13\% de los casos se distribuían por varias otras situaciones residuales e intermediarias. 
Entre los individuos que tienen redes grandes y pequeñas, con sociabilidad local y primaria, se encuentran sobre-representados individuos más jóvenes y mayores, respectivamente. En el primer caso, la escolaridad tiende a ser mayor que el promedio, y son más frecuentes los estudiantes y los no emigrantes. En el segundo, la escolaridad es baja, y están sobre-representados los jubilados, las dueñas de casa y los emigrantes (con elevadas presencias de coterráneos). En términos generales, por lo tanto, estas situaciones relacionales se ligan frecuentemente a individuos con integración social más baja. Ambas las situaciones son más frecuentes en localidades no segregadas (57 y $70 \%$, respectivamente).

La situación intermediaria es la más común e incluye individuos con características sociales próximas al promedio del universo estudiado en términos de edad y escolaridad. Merecen destaque las elevadas presencias de emigrantes, autónomos y desempleados. Entre los que trabajan, la mayoría trabaja en la propia localidad donde vive.

La última situación, por fin, incluye principalmente individuos adultos con escolaridad relativamente elevada y mejor inserción en el mercado laboral, lo que incluye una proporción elevada de empleados con contrato, aunque también autónomos y empleados sin contrato. Estos individuos tienden con alguna frecuencia a trabajar fuera de la comunidad. Esta situación social, por lo tanto, se presenta asociada con frecuencia a individuos más integrados socialmente.

Esta situación se encuentra sobre-representada en las localidades más segregadas y, aunque se presenta en el $17 \%$ de las áreas, alcanza el $33 \%$ en Guarulhos, el $27 \%$ en Cidade Tiradentes y el $20 \%$ en Taboao. Así, es posible afirmar que el efecto de la segregación es más complejo que lo sugerido por la idea de un impacto negativo y directo $y$, aunque no existen en promedio grandes diferencias entre las redes de localidades segregadas y no segregadas, algunos individuos segregados presentan patrones relacionales menos locales y menos homófilos, lo que demuestra que las redes pueden estar integrando una parte de los individuos más aislados por el espacio.

\section{Conclusión}

El artículo mostró que, cuando comparadas con las redes de la clase media, las redes personales de los individuos pobres tienden a ser menores, menos cohesionadas, más locales y menos variadas en términos de sociabilidad. A pesar de ello, las redes varían sustancialmente entre sí, siendo muy difícil encontrar relaciones directas entre variables socioeconómicas y patrones de relación. 
La construcción de las tipologías de redes y de sociabilidades sugiere la presencia de patrones de relación bastante nítidos (y diversos entre sí). En este sentido, incluso entre las redes de individuos en situación de pobreza se observan redes grandes y con sociabilidad más variada, así como redes menores y con aislamiento urbano significativo. Es interesante destacar que el tamaño, la variabilidad de la sociabilidad y el localismo no caminan juntos, y que las redes mayores son mucho más locales y presentan baja variabilidad de la sociabilidad. Estas dos características también están presentes en las redes muy pequeñas. Las que tienen tamaño medio son las que presentan menor localismo y mayor variabilidad social. En lo que respecta a la sociabilidad de los más pobres, los datos también sugieren la existencia de patrones muy diversificados. Si por un lado podemos notar la existencia de patrones de sociabilidad muy locales y basados en vínculos primarios (básicamente familia, vecindario y amistades), una parte significativa de las redes presenta sociabilidad poco local y producida sustancialmente en ambientes organizacionales o institucionales (trabajo, iglesia, asociaciones).

Confirmando resultados previos presentes en la literatura, la relación entre espacio urbano y redes indica que las redes de los individuos pobres son marcadas por intenso localismo, diferentemente de las de la clase media, dónde prácticamente no hay localismo y vecindario, y la propia idea de comunidad o incluso el criterio dentro/fuera no tiene sentido alguno.

La hipótesis de un efecto directo de la segregación social en el espacio sobre las redes, por fin, no se ha verificado, y la segregación parece no impactar directa y mecánicamente el tamaño, la actividad y la estructura de las redes. Sin embargo, aunque las redes no varíen sustancialmente en términos promedios según el grado de segregación de las localidades estudiadas, las redes de tamaño medio con sociabilidad menos local y menos primaria tienden a estar más presentes en localidades segregadas. Esto sugiere que las redes integran potencialmente una parte de los individuos que están segregados, ayudando a combatir los efectos del aislamiento social.

\section{Bibliografía}

Bearman, R.; Moody, J. \& Stovel, K. (2004) "Chains of affection: the structure of adolescent romantic and sexual networks". American Journal of Sociology, vol. 110 (1): 44-91.

Beggs, J. (1996) "Revising the rural-urban contrast: personal networks in nonmetropolitan and metropolitan settings". Rural sociology, 61:306-325.

Bidart, C. \& Lavenu, D. (2005) "Evolution of personal networks and life events". Social Networks, 27 (4): 359-376. 
Borgatti, S.; Everett, M. \& Freeman, L. (2002) Ucinet for Windows: software for social network analysis. Harvard, MA, Analytic Technologies.

Campbell, K. \& Lee, B. (1992) "Sources of Personal Neighbor Networks: Social Integration, Need, or Time?" Social Forces, vol. 70 (4): 1077-1100.

Emirbayer, M. (1997) "Manifesto for a relational sociology". American Journal of Sociology, 103 (2): 231-317.

Fontes, B. \& Eichner, K. (2004) "A formação de capital social em uma comunidade de baixa renda". Redes: Revista Hispana para el Análisis de Redes Sociales, vol. 7 (2). Internet: http://revista-redes.rediris.es

Freeman, L. (2004) The development of social network analysis. Vancouver, Empirical Press.

Grosetti, M. (2005) "Where do social relations come from? A study of personal networks in the Toulouse area of France". Social Networks, 27(4): 289-300.

Gurza Lavalle, A.; Castello, G. \& Bichir, R. (2007) "Redes y Capacidad de Acción en la Sociedad Civil. El caso de São Paulo, Brasil". Redes - Revista Hispana para el Análisis de Redes Sociales, 12: 1-38.

Hanneman, R. \& Riddle, M. (2005) Introduction to social network methods. Riverside, CA, University of California.

Heinz, J.; Laumman, E.; Nelson, R. \& Salizbury, R. (1997) The hollow core: private interests in national policy making. Cambridge, Harvard University Press.

Hedstrom, P.; Sandell, R. \& Stern, C. (2000) "Meso-level networks and the diffusion of social movements". American Journal of Sociology, 106(1): 145-172.

Kadushin, C. (1995) "Friendship Among the French Financial Elite". American Sociological Review, 60: 202-221.

Kirschbaum, C. (2006) Campos organizacionais em transformação: o caso do Jazz americano e da Música Popular Brasileira. Fundação Getulio Vargas, Tesis Doctoral.

Laumann, E. \& Knoke, D. (1987) The organizational state: social choice in national policy domains. Madison, The Wisconsin University Press.

Marques, E.; Bichir, R.; Pavez, T.; Zoppi, M.; Moya, E. \& Pantoja, I. (2008) "Personal Networks and Urban Poverty: Preliminary Findings". Brazilian Political Science Review, vol. 2(1): 10-34.

Marques, E. (2000) Estado e redes sociais: Permeabilidade e coesão nas políticas urbanas no Rio de Janeiro. Rio de Janeiro, Ed. Revan/Fapesp.

Marques, E. (2003) Redes sociais, Instituições e Atores Políticos no governo da cidade de São Paulo. São Paulo, Ed. Annablume.

Marques, E. (2005) “Elementos conceituais da segregação urbana e da ação do Estado". In: __ \& TORRES, H. São Paulo: segregação, pobreza urbana e desigualdade social. São Paulo, Ed. Senac, p. 19.

Marques, E. (2009) Redes sociais, segregação e pobreza em São Paulo. São Paulo: Edusp.

Marques, E. (2008) Do social networks matter for poverty? Artículo presentado en el Encuentro del RC21 "Landscapes of Global Urbanism: Power, Marginality, and Creativity" realizado en Tóquio, Japão.

Maya-Jariego, I. (2003) "A general typology of the personal networks of immigrants with less than 10 years living in Spain". Trabajo presentado en el XXIII Sunbelt Conference. 
McPherson, M.; Smith-Lovin, L. \& Cook, J. (2001) "Birds of a feather: homophily in social networks". Annual Review of Sociology, 27: 415-444.

Mische, A. (2008) Partisal Publics. Princeton: Princeton University Press.

Moore, G. (1990) "Structural determinants of men's and women's personal networks". American Sociological Review, vol. 55: 726-35.

Nazareno, L. (2005) Redes sociais e coalizão de poder em Curitiba (1985-2004). FFLCH/USP, DCP, Máster en Ciencias Políticas.

Pavez, T. (2006) Políticas públicas e ampliação de capital social em comunidades segregadas: o programa Santo André Mais Igual. FFLCH/USP, DCP, Máster en Ciencias Políticas.

Schneider, M.; Scholz, J.; Lubell, M.; Minduta, D. \& Edwardsen, M. (2003) “Building consensual institutions: networks and the National Estuary Program". American J ournal of Political Science, 47 (1): 143-158.

Scott, J. (1992) Social Network analysis. Newbury Park, Sage Publications.

Silva, M. (2003) Redes sociais intra-organizacionais informais e gestão: um estudo nas áreas de manutenção e operação da Planta HYCO-8. EA/UFBA, Máster.

Simmel, G. (1972) [1908] "El cruce de los circulos sociales". En: Sociología, 2. Estudios sobre las formas de socialización. Alianza Universidad, p. 41.

Soares, R. (2009) Estado, segregação e desigualdade: Um estudo sobre o impacto das políticas de habitação a partir das redes sociais da favela Guinle, Guarulhos. FFLCH/USP, DCP, Máster en Ciencias Políticas.

Toledo, D. (2005) O empresariado paulista nos anos 90. FFLCH/USP, DS, Máster en Sociologia.

Waserman, S. \& Faust, K. (1994) Social Network Analysis: Methods and Applications. Cambridge, Cambridge University Press.

Weber, M. 1999 [1922]. Economia e sociedade: fundamentos da sociologia compreensiva. São Paulo, UNB/Imprensa Oficial. 
Anexo

\begin{tabular}{|c|c|c|c|c|c|}
\hline \multirow[b]{2}{*}{ Indicadores } & \multicolumn{5}{|c|}{ Tipos de redes } \\
\hline & $\begin{array}{l}\frac{y}{0} \\
\frac{0}{0} \\
\frac{0}{\sigma}\end{array}$ & 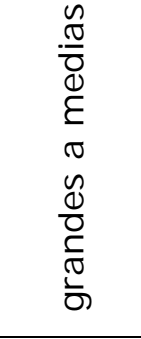 & $\begin{array}{l}\frac{n}{0} \\
\frac{.0}{0} \\
\frac{\pi}{2}\end{array}$ & 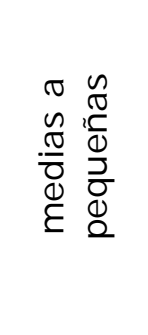 & 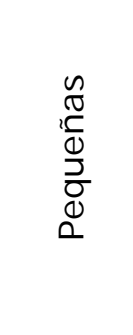 \\
\hline $\mathrm{N}^{\circ}$ de nodos & 131 & 85 & 61 & 40 & 22 \\
\hline $\mathrm{N}^{0}$ de vínculos & 282 & 176 & 123 & 84 & 36 \\
\hline diámetro & 8,0 & 7,6 & 7,2 & 5,7 & 4,8 \\
\hline Densidad & 0,049 & 0,046 & 0,078 & 0,105 & 0,176 \\
\hline $\begin{array}{l}\text { coeficiente de } \\
\text { aglomeración }\end{array}$ & 0,32 & 0,36 & 0,48 & 0,47 & 0,51 \\
\hline índice de centralización & 16,9 & 20,6 & 31,2 & 39,3 & 54,6 \\
\hline $\mathrm{N}^{\circ}$ de 2 -clans $/ \mathrm{N}^{\circ}$ de nodos & 0,9 & 0,574 & 0,452 & 0,432 & 0,291 \\
\hline $\mathrm{N}^{\circ}$ de 3 -clans/ $\mathrm{N}^{\circ}$ de nodos & 0,5 & 0,401 & 0,302 & 0,259 & 0,182 \\
\hline tam. eficiente de la red ego & 19,5 & 19,1 & 19,0 & 14,7 & 8,5 \\
\hline densidad de la red ego & 20,0 & 23,5 & 20,4 & 16,3 & 9,9 \\
\hline grado medio & 2,2 & 2,1 & 2,0 & 2,1 & 1,7 \\
\hline Información & 1,08 & 1,27 & 1,16 & 1,58 & 1,33 \\
\hline índice E_I de los contextos & 0,204 & 0,340 & 0,289 & 0,339 & 0,313 \\
\hline índice E_I de las esferas & 0,209 & 0,360 & 0,262 & 0,312 & 0,236 \\
\hline $\mathrm{N}^{\circ}$ total de contextos & 4,6 & 4,8 & 4,7 & 4,5 & 3,8 \\
\hline $\mathrm{N}^{\circ}$ total de esferas & 4,4 & 4,4 & 4,1 & 3,9 & 3,0 \\
\hline índice E_I de localidad & $-0,335$ & $-0,228$ & $-0,211$ & $-0,150$ & $-0,067$ \\
\hline $\mathrm{N}^{0}$ de casos & 14 & 21 & 59 & 68 & 47 \\
\hline $\begin{array}{l}\text { \% de pers. externas al } \\
\text { localidad }\end{array}$ & 31,4 & 31,2 & 38,7 & 39,7 & 35,4 \\
\hline
\end{tabular}

Tabla 2. Indicadores promedio por tipo de red.

Fuente: Cálculo propio a partir del material empírico recogido. 